
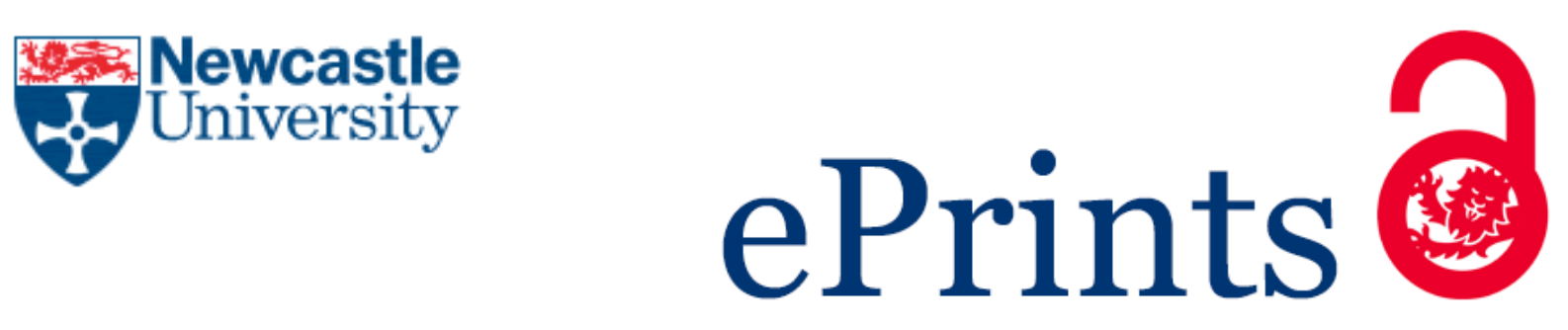

Millen D, Pinhanez C, Bianchi S, Kaye J, Vines J. Collaboration and Social Computing in Emerging Financial Services. In: ACM Conference on ComputerSupported Cooperative Work and Social Computing (CSCW 2015) Companion. 2015, Vancouver, Canada: ACM Press.

\title{
Copyright:
}

(C) ACM, 2015. This is the author's version of the work. It is posted here by permission of ACM for your personal use. Not for redistribution. The definitive version was published in ACM Conference on Computer-Supported Cooperative Work and Social Computing (CSCW 2015) Companion. DOI: $10.1145 / 2685553.2685562$

DOI link to article:

http://dx.doi.org/10.1145/2685553.2685562

Date deposited:

$10 / 04 / 2015$ 


\section{Collaboration and Social Computing in Emerging Financial Services}

\author{
David R Millen \\ IBM Research \\ Rua Tutoia 1157 \\ Sao Paulo, SP 04007-900 Brazil \\ dmillen@br.ibm.com \\ Claudio Pinhanez \\ IBM Research \\ Rua Tutoia 1157 \\ Sao Paulo, SP 04007-900 Brazil \\ csantosp@br.ibm.com \\ Jofish Kaye \\ Yahoo Labs 701 1st Ave \\ Sunnyvale CA 94048 \\ acm@jofish.com \\ Silvia Cristina Sardela \\ Bianchi \\ IBM Research \\ Rua Tutoia 1157 \\ Sao Paulo, SP 04007-900 Brazil \\ ssardela@br.ibm.com \\ John Vines \\ Culture Lab, \\ School of Computing Science, \\ Newcastle University, UK \\ john.vines@ncl.ac.uk
}

\begin{abstract}
In this workshop we consider new financial services from a CSCW and Social Computing perspective. We will bring together researchers, policy-makers and practitioners who are interested in new financial services such as mobile payments, digital money, microfinance, mobile commerce, and the adoption and use of these new services by special sub-populations. Also of interest in this workshop will be the use of social analytics to understand financial markets and create new services. We also aim to explore the underlying group and network mechanisms that promote trust and enable commerce (e.g., solidarity lending groups). The workshop will contribute to the continued development of a network of researchers and practitioners interested in the intersection of $\mathrm{HCI}$ and financial services.
\end{abstract}

\section{Author Keywords}

Financial Interaction; P2P lending; digital money; mobile payments; microfinance.

\section{ACM Classification Keywords}

H.5.m. Information interfaces and presentation (e.g., $\mathrm{HCI}$ ): Miscellaneous.

\section{Introduction}

Innovation in financial services presents many interesting challenges for CSCW and Social Computing. 
Mobile commerce encourages new design solutions that need to span consumer devices ranging from simple feature phones to full function web-enabled smart devices. New mobile money technologies such as MPesa, digital wallets, online banking and crytocurrencies such as bitcoin (bitcoin.org) invite novel interface and systems designs [3][7]. Exciting new forms of lending have also emerged such as "solidaritygroup" backed micro-finance, and various forms of online peer-to-peer lending [4][8].

Financial transactions are fundamentally embedded in a multi-person context and involve the coordinated action of multiple actors. For example, basic payment systems involve a buyer and a seller. The transaction, however, is completed within the context of a financial system that includes organizations (e.g., banks, governments) and the coordination of a rich network of other groups (e.g., competitors, suppliers, transportation providers). Understanding this larger context is required to design financial services that will be readily adopted and provide benefits to the greater financial ecosystems.

Many financial services are also based on very interesting social networks. Community currencies (see, for example [2][6]) have been developed to promote within-group economic activity, which some argue will spur local economic growth. Solidarity groups have been used to secure credit from groups who are typically unable to qualify for traditional loans from traditional banks. The nature of the relationships between members in the group is a very interesting and unexplored social network research challenge (e.g., multifaceted network models of solidarity groups).

\section{Workshop Objectives}

In this workshop, we bring together researchers working in various areas of financial services design. There is evidence of growing interest in this area by a recent $\mathrm{CHI}$ SIG and workshop on similar topics [1].

In this workshop, we aim to explore the relationship between $\mathrm{HCI}$ and financial services with an emphasis on three main topics:

1) Financial Services for Special Groups: How do we design new financial services for special populations? Of particular interest are older people [9], those on limited incomes and unbanked populations.

2) Use and adoption of new financial technologies: How do we measure and support the adoption of new technologies used in financial services [5]? How can we deal with issues of trust, privacy and security in new systems?

3) Social analytics for financial services: How can we effectively use social media and social network analytics for development of new financial services? This could include exploring financial life event detection and modeling using social media data streams, or social listening techniques for detecting product and service trends (among many others).

We are also particularly interested in hearing about case studies of novel services that have been studied in the field. 


\section{Workshop Topics}

At the workshop, we are aiming to explore the following specific topics, with the hope of identifying guidance and insight to drive future research and innovations in the context of collaborative and social computing approaches to financial service design:

- How can new interaction technologies be used to create new financial services or change existing services?

- What are the barriers and accelerators for adoption of new financial services? How can social computing and collaborative technologies support new forms of financial literacy education?

- What is the role of social context and social relationships in the development of financial services? How can solidarity lending practices be improved and expanded?

- New approaches for research into financial behavior, including novel elicitation practices such as financial games, financial probes, and improvisation.

- What are the challenges for populations such as older people or people with disabilities, whose needs and values may differ from the archetypes account holders banks provide for?

- Financial inclusion and services for the unbanked.
- New forms of money, including digital cash and community currencies.

- Financial social analytics: how can social analytic approaches be used to understand individual and groups financial behavior

\section{Organizing Committee}

David $\mathbf{R}$ Millen is a senior researcher at IBM Research in Brazil where his current research interests are in understanding social networks in financial systems.

Claudio Pinhanez is a researcher, professor, and media artist. He is the senior manager of the Social Data Analytics group of IBM Research-Brazil, working on Social Media and Networks, Cognitive Computing, Service Science, and Human-Computer Interfaces.

Jofish Kaye is Senior Research Scientist at Yahoo Labs, and his work revolves around studies of how people connect with each other. He is currently studying how people understand and think about their everyday personal and family finances.

Silvia Cristina Sardela Bianchi is a researcher at IBM Research in Brazil - Social Data Analytics group. Her current research interests include peer-to-peer lending, digital currencies, social networks and cognitive computing.

John Vines is a Lecturer in the School of Computing Science at Newcastle University, where he is based in the Digital Interaction group in Culture Lab. His research is focused on design methods in the context of digital civic participation and financial inclusion. 


\section{References}

[1] Kaye, J., Vertesi, J., Ferreira, J., Brown, B., and Perry, M. \#CHImoney: Financial Interactions, Digital Cash, Capital Exchange and Mobile Money. CHI '14 Extended Abstracts on Human Factors in Computing Systems, ACM (2014), 111-114.

[2] Knowles, B., Lochrie, M., Coulton, P., and Whittle, J. BARTER: Promoting Local Spending Behavior. CHI'14 Extended Abstracts on Human Factors in Computing Systems, ACM (2014), 1933-1938.

[3] Medhi, I., Gautama, S.N.N., and Toyama, K. A Comparison of Mobile Money-transfer UIs for Nonliterate and Semi-literate Users. Proceedings of the SIGCHI Conference on Human Factors in Computing Systems, ACM (2009), 1741-1750.

[4] Parikh, T.S., Javid, P., K., S., Ghosh, K., and Toyama, K. Mobile Phones and Paper Documents: Evaluating a New Approach for Capturing Microfinance Data in Rural India. Proceedings of the SIGCHI Conference on Human Factors in Computing Systems, ACM (2006), 551-560.

[5] Schierz, P.G., Schilke, O., and Wirtz, B.W. Understanding consumer acceptance of mobile payment services: An empirical analysis. Electronic
Commerce Research and Applications 9, 3 (2010), 209-216.

[6] Seyfang, G. and Longhurst, N. Growing green money? Mapping community currencies for sustainable development. Ecological Economics 86, (2013), 65-77.

[7] Sherman, M. An Introduction to Mobile Payments: Market Drivers, Applications, and Inhibitors. Proceedings of the 1st International Conference on Mobile Software Engineering and Systems, ACM (2014), 71-74.

[8] Sinanan, J. Lenders, Borrowers and Fellows: Personal Narrative and Social Entrepreneurship in Online Microfinance. Proceedings of the 21st Annual Conference of the Australian ComputerHuman Interaction Special Interest Group: Design: Open 24/7, ACM (2009), 293-296.

[9] Vines, J., Blythe, M., Dunphy, P., et al. Cheque Mates: Participatory Design of Digital Payments with Eighty Somethings. Proceedings of the SIGCHI Conference on Human Factors in Computing Systems, ACM (2012), 1189-1198. 